УДК 504.53.052

DOI 10.18413/2712-746X-2020-45-4-742-749

\title{
К вопросу об адвокации прав граждан при оказании психиатрической помощи
}

\author{
Лебедь А.В. \\ Региональная благотворительная общественная организация \\ «Центр лечебной педагогики» \\ 119311, Россия, г. Москва, ул. Строителей, д. 17-Б \\ E-mail: lebed.ania@yandex.ru
}

\begin{abstract}
Аннотация. По результатам анализа теоретических подходов и формальных положений рассмотрен феномен адвокации прав граждан при оказании психиатрической помощи на основе международно-правового и внутригосударственного регулирования, которое формирует предпосылки для развития правозащитных процессов в отношении лиц, страдающих психическими расстройствами, при условии соответствующей направленности политической воли. Авторы указывают на наличие формальных условий для развития системы защиты прав указанной категории граждан при недостатке организационных мер для ее построения со стороны государства. Приведена схема работы механизма службы защиты прав получателей социальных услуг, страдающих психическими расстройствами и проживающих в стационарных организациях социального обслуживания.
\end{abstract}

Ключевые слова: страдающие психическими расстройствами, адвокация прав, служба защиты прав пациентов, стационарные организации социального обслуживания.

Для цитирования: Лебедь А.В. 2020. К вопросу об адвокации прав граждан при оказании психиатрической помощи. NOMOTHETIKA: Философия. Социология. Право. 45 (4): 742-749. DOI $10.18413 / 2712-746 \mathrm{X}-2020-45-4-742-749$

\section{Advocacy for the rights of citizens in the provision of psychiatric care}

\author{
Anna V. Lebed \\ Regional nonprofit social organization "Center for Curative Pedagogics" \\ 17-B Stroiteley street, Moscow, Russia, 119311 \\ E-mail: lebed.ania@yandex.ru
}

\begin{abstract}
Based on the analysis of theoretical approaches and formal provisions, the article examines the phenomenon of advocacy for the rights of citizens in the provision of psychiatric care on the basis of international legal and domestic regulation, which forms the preconditions for the development of human rights processes in relation to persons suffering from mental disorders, subject to the appropriate direction of political will. The authors point to the existence of formal conditions for the development of a system for protecting the rights of this category of citizens in the absence of organizational measures from the state to build it. The article provides a diagram of the work of the mechanism of the service for protecting the rights of recipients of social services suffering from mental disorders and living in stationary social service organizations.
\end{abstract}

Key words: people with mental disorders, advocacy, patient advocacy, stationary social service organizations.

For citation: Lebed A.V. 2020. Advocacy for the rights of citizens in the provision of psychiatric care. NOMOTHETIKA: Philosophy. Sociology. Law series. 45 (4): 742-749 (in Russian). DOI 10.18413/2712-746X-2020-45-4-742-749 


\section{Введение}

Описывая адвокацию и ее терминологическое значение, мы неизбежно столкнемся с разнообразием дефиниций, характерных для различных государств, культур, временных периодов и политических режимов. Этимологически термин «адвокация» зародился в те далёкие времена, когда общепризнанные древнеримские ораторы действовали в качестве адвокатов или произносили речи специально для того, чтобы призвать к чьим-то делам и убеждениям. Термин происходит от латинского слова advocare и буквально означает призыв к оказанию поддержки.

В современной трактовке термин «адвокация» употребляется при определении «процесса социальных изменений, влияющего на взгляды, отношения в обществе и соотношение сил, укрепляющего гражданское общество и открытие демократических пространств» ${ }^{1}$. Употребление данной дефиниции набирает популярность при обозначении стремления к достижению поставленных целей в интересах определенных социальных групп (уязвимых групп, персонала организаций, инвалидов, лиц с психическими расстройствами и пр.).

В России адвокация прав граждан при оказании психиатрической помощи является направлением правозащитной деятельности, не получившим должного развития ввиду значительной степени стигматизации лиц, страдающих психическими расстройствами, и системы оказания психиатрической помощи в целом. Между тем необходимые предпосылки для ее развития и распространения существуют уже более двадцати лет и закреплены в Законе Российской Федерации от 2 июля 1992 года № 3185-1 «О психиатрической помощи и гарантиях прав граждан при ее оказании» ${ }^{2}$. Статья 38 указанного Закона гласит: «Государством создается независимая от органов исполнительной власти в сфере охраны здоровья служба защиты прав пациентов, находящихся в медицинских организациях, оказывающих психиатрическую помощь в стационарных условиях. Представители этой службы защищают права пациентов, находящихся в медицинских организациях, оказывающих психиатрическую помощь в стационарных условиях, принимают их жалобы и заявления, которые разрешают с руководителем указанной медицинской организации либо направляют в зависимости от их характера в органы представительной и исполнительной власти, прокуратуру или суд».

Тематика психического здоровья и прав граждан, страдающих психическими расстройствами, заинтересовала зарубежное научное сообщество раньше, чем это произошло в России [Sales B.D., Shuman D.W., 1994; Perlin M.L., 1994; Barker A., 1997].

Начиная с 2000-х гг. тема специфики защиты прав граждан, страдающих психическими расстройствами, активно разрабатывается в отечественной правовой науке. Об этом свидетельствуют многочисленные научные работы Аргуновой Е.Н. [2009], Абрамян С.К. [2009] Тарасовой Е.Н. [2017], Котарева С.Н. [2008], Лариной А.Н., Верещагиной О.Н., Анисимовой А.А. [2016], Козловой Н.В. [2018], Семериковой П.В [2018] и других авторов, имеющие теоретическое и прикладное значение. Однако авторы в своих исследованиях нечасто обращаются к развитию специальных институтов, способствующих защите прав рассматриваемой категории лиц.

Много лет столь значительная норма права практически не применялась при наличии информации о множестве нарушений прав граждан, которым оказывается психиатрическая помощь в психиатрических больницах и психоневрологических интернатах ${ }^{3}$. Ука-

1 What is advocacy and how can it help? // https://www.culturepartnership .eu/publishing/advocacy-course/what-is-advocacy

${ }^{2} \mathrm{http} / / / \mathrm{www}$. consultant.ru/document/cons_doc_LAW_4205/

${ }^{3}$ ПНИ и пытки. Что увидел Европейский комитет по предотвращению пыток в российских ПНИ // https://www.kommersant.ru/doc/4141180 
занные факты дают нам почву для осмысления важности адвокации прав граждан при оказании психиатрической помощи и разработки подходов к реализации положений ст. 38 Закона Российской Федерации «О психиатрической помощи и гарантиях прав граждан при ее оказании».

\section{Права граждан при оказании им психиатрической помощи как объект охраны и защиты}

Одним из необходимых условий функционирования личности как полноценного представителя человеческого общества является надлежащее состояние ее психического здоровья [Аргунова, 2014, с. 17]. Психическое здоровье и психическое благополучие - это важнейшие предпосылки для хорошего качества жизни и продуктивной деятельности отдельных лиц, семей, местных сообществ и народов в целом, так как они позволяют людям воспринимать свою жизнь как полноценную и значимую и являться активными и созидательными членами общества ${ }^{1}$.

Статья 41 Конституции Российской Федерации гарантирует право каждого на охрану здоровья. Охрана здоровья граждан - это система мер политического, экономического, правового, социального, научного, медицинского, в том числе санитарно-противоэпидемического (профилактического) характера, осуществляемых органами государственной власти Российской Федерации, органами местного самоуправления, организациями, их должностными лицами и иными лицами, гражданами в целях профилактики заболеваний, сохранения и укрепления физического и психического здоровья каждого человека, поддержания его долголетней активной жизни, предоставления ему медицинской помощиㄹ․

Среди принципов охраны здоровья граждан в рассматриваемом контексте основополагающими являются соблюдение прав граждан в сфере охраны здоровья и обеспечение связанных с этими правами государственных гарантий, приоритет интересов пациента при оказании медицинской помощи и социальная защищенность граждан в случае утраты здоровья (Федеральный закон «Об основах охраны здоровья граждан в Российской Федерации», ст. 4).

Помимо государственного регулирования оказания психиатрической помощи, существует обширное количество международно-правовых актов, касающихся прав граждан, страдающих психическими расстройствами, в том числе приведшими к инвалидизации. В Европейской декларации по охране психического здоровья, принятой в 2005 году, изложены политика и приоритетные задачи в области охраны психического здоровья, а также практическая деятельность и обязательства министров здравоохранения государствчленов европейского региона ВОЗ в этой сфере.

Согласно Декларации для достижения целей обеспечения психического благополучия и социальной интеграции лиц с проблемами психического здоровья, помимо прочего, необходимы борьба со стигматизацией и дискриминацией, обеспечение защиты прав человека и человеческого достоинства и внедрение законодательства для того, чтобы люди, подвергающиеся риску, или лица с психическими проблемами и инвалидностью имели возможности для полноценного и равноправного участия в жизни общества ${ }^{3}$.

${ }^{1}$ Европейская декларация по охране психического здоровья, Хельсинки, Финляндия, 12 15 января 2005 г., 1 // https://www.euro.who.int/_data/assets/pdf_file/0011/88598/E85445R.pdf?ua=1

${ }^{2}$ Федеральный закон от 21 ноября 2011 г. № 323-Ф3 «Об основах охраны здоровья граждан в Российской Федерации» // http://www.consultant.ru /cons/cgi/online.cgi?req=doc\&ts $=51536222403560281156167697 \&$ cacheid $=$ C2A8BD90413F9732497D2F1175F5E421\&mode $=$ splus $\& b$ ase $=\mathrm{LAW} \& \mathrm{n}=354521 \& \mathrm{rnd}=\mathrm{BB} 80 \mathrm{AB} 63 \mathrm{ADDF} 162825 \mathrm{C} 69 \mathrm{D} 4 \mathrm{E} 8 \mathrm{BD} 76 \mathrm{~F} 9 \mathrm{~A} \# 1 \mathrm{zw} 73 \mathrm{z} 8 \mathrm{ryhh}$

${ }^{3}$ Европейская декларация по охране психического здоровья. $1 / /$ https://www.euro.who.int/ _data/assets/pdf_file/0011/88598/E85445R.pdf?ua=1 
Статья 19 Конвенции ООН о правах инвалидов распространяется на лиц, страдающих психическими расстройствами, при наличии у них инвалидности и предусматривает, что инвалиды имеют право жить в обществе и участвовать в жизни общества в качестве равноправных граждан. Право на жизнь в обществе подтверждает, что инвалиды не ограничены в своем выборе и возможностях из-за собственной несостоятельности, а скорее ограничены в результате социальных и физических барьеров для равного участия в общественной жизни ${ }^{1}$.

Лица, страдающие психическими расстройствами, чаще других инвалидов помещаются в специализированные учреждения против их воли, они лишены возможности принимать решения о своей жизни или участвовать в мероприятиях в качестве равноправных граждан, часто лишены права жить самостоятельно. Этот процесс обозначают термином «институционализация». Институционализация усиливает стигматизацию и предвзятое отношение к инвалидам, укрепляя ложное представление о том, что они не в состоянии участвовать в жизни общества.

Сегрегация также является нарушением прав человека, так как она лишает людей права независимой жизни. Сегрегация в учреждениях долгосрочного пребывания, таких как психиатрические больницы, психоневрологические интернаты, считается наиболее значительным нарушением прав многих детей и взрослых с ограниченными возможностями здоровья.

В некоторых государствах, таких как Российская Федерация, зачастую учреждения долгосрочного пребывания расположены в отдаленных сельских районах. Это означает, что пациенты редко, если вообще когда-либо принимают гостей и практически не имеют связи с внешней средой - во многих случаях до конца своей жизни.

Учреждения, в которых проживают инвалиды, лишают их права выбора места проживания, способа проживания и общения с другими. Жизнь в учреждениях по своей сути строго контролируется.

Инвалиды, проживающие в стационарных организациях социального обслуживания, сталкиваются с серьезными проблемами при осуществлении своих основных прав на участие в общественной жизни. В частности, лица, находящиеся в учреждениях, лишены полного и равноправного доступа к образованию и занятости - двух основных методов участия в социальной жизни. Институциализированные лица часто лишены возможности получения образования. Будучи исключенными из системы образования, они получают обособленное или низкого качества образование. Кроме того, инвалиды часто лишены возможности работать в обществе.

Лица с ограниченными возможностями здоровья, проживающие в интернатных учреждениях, подвергаются более высокому риску пыток и других жестоких, бесчеловечных или унижающих достоинство видов обращения и наказания, что нарушает статью 15 Конвенции о правах инвалидов ${ }^{2}$. В подтверждение вышеуказанных фактов 24 сентября 2019 года был опубликован Доклад Европейского комитета по предупреждению пыток и бесчеловечного или унижающего достоинство обращения или наказания (ЕКПП) о положении людей с психическими заболеваниями в российских психиатрических больницах и

${ }^{1}$ Конвенция ООН о правах инвалидов (принята резолюцией 61/106 Генеральной Ассамблеи от 13 декабря 2006 года) // https://www.un.org/ru/documents/decl_conv/conventions /disability.shtml

${ }^{2}$ Охрана здоровья и права человека: ресурсное пособие. Центр здоровья и прав человека имени Франсуа-Ксавье Баню и Фонд открытого общества, 2015, Перевод с английского языка, 9.23 . 
психоневрологических интернатах ${ }^{1}$. Каждые четыре года делегации ЕКПП посещают государства, ратифицировавшие Европейскую конвенцию по предупреждению пыток и бесчеловечного или унижающего достоинство обращения или наказания ${ }^{2}$. В ходе минувшей проверки ЕКПП были выявлены факты жестокого обращения и физического насилия в отношении получателей социальных услуг, переполненность отделений в зданиях психоневрологических интернатов, низкое качество оказываемой медицинской и психологической помощи, очевидное отсутствие доступа к адекватной стоматологической помощи, нарушение законодательства об опеке в отношении недееспособных граждан, неукомплектованность интернатных учреждений специалистами, в частности психологами, психиатрами, специальными педагогами, специалистами по трудотерапии, физиотерапевтами, социальными работниками, младшим медицинским персоналом.

Анализ плачевных данных, изложенных представителями Европейского комитета по предупреждению пыток и бесчеловечного или унижающего достоинство обращения или наказания, привлек внимание авторов к вопросам о возможностях оказания помощи в защите прав граждан, проживающих в стационарных организациях социального обслуживания и получающих там психиатрическую помощь, которые предоставляет российской законодательство.

\section{Перспективы деятельности службы защиты прав пациентов психиатрических стационарных учреждений}

В своей статье «Обеспечение и защита прав граждан, страдающих психическими расстройствами» Абрамян С.К. справедливо указывает: «Государством до сих пор не создана независимая от органов здравоохранения служба защиты прав пациентов, находящихся в психиатрических стационарах. Данное Правительству Российской Федерации еще в 1992 г. поручение о разработке и утверждении положения об этой службе не выполнено» [Абрамян, 2009, с. 104]. Попытки организации деятельности Службы защиты прав пациентов психиатрических стационарных учреждений в соответствии со ст. 38 Закона Российской Федерации от 2 июля 1992 года № 3185-1 «О психиатрической помощи и гарантиях прав граждан при ее оказании» уже неоднократно были предприняты. Деятельность подобной службы, организованной представителями гражданского общества, на протяжении нескольких лет отрабатывалась в ходе реализации пилотного проекта на базе нескольких психоневрологических интернатов города Москвы и продемонстрировала высокий уровень востребованности и результативности.

Был разработан проект соответствующего Федерального Закона «О службе по защите прав пациентов, находящихся в медицинских организациях, оказывающих психиатрическую помощь в стационарных условиях, и граждан, проживающих в стационарных организациях социального обслуживания для лиц, страдающих психическими расстройствами» ${ }^{3}$. Однако после проведения многочисленных обсуждений и слушаний до настоящего времени указанный федеральный закон не был принят.

В ходе обсуждений возникал закономерный вопрос о том, в какой структуре могла бы функционировать указанная служба. С одной стороны, она должна быть государствен-

${ }^{1}$ Report to the Russian Government on the visit to the Russian Federation carried out by the European Committee for the Prevention of Torture and Inhuman or Degrading Treatment or Punishment (CPT) from 19 to 29 October 2018. https://rm.coe.int/168097e387

${ }^{2}$ Европейская конвенция по предупреждению пыток и бесчеловечного или унижающего достоинство обращения или наказания ETS № 126 (Страсбург, 26 ноября 1987 г.) // https://base.garant.ru/1305480/

${ }^{3} \mathrm{http}: / /$ www.consultant.ru/cons/cgi/online.cgi?req=doc\&base=PRJ\&n=138821\#07026035490441 975 
ной, при этом сохраняя независимость от Министерства здравоохранения, Министерства труда и социальной защиты Российской Федерации, то есть фактически от тех учреждений, в которых проходят лечение или постоянно проживают лица, страдающие психическими расстройствами. Неоднократно была высказана позиция о том, что структура уполномоченного по правам человека была бы наиболее логичной институцией, в рамках которой возможно создание службы защиты прав пациентов.

Несмотря на отсутствие подробной регламентации деятельности службы на федеральном уровне, закрепление нормы о возможности создания независимой от органов исполнительной власти в сфере охраны здоровья службы защиты прав пациентов дает право органам исполнительной власти субъектов Российской Федерации создавать подобные службы и регламентировать их деятельность на основании Закона Российской Федерации «О психиатрической помощи и гарантиях прав граждан при ее оказании». Например, с целью защиты прав получателей социальных услуг, страдающих психическими расстройствами и проживающих в стационарных организациях социального обслуживания, служба защиты прав может быть создана органами государственной власти субъектов Российской Федерации в сфере социального обслуживания. Служба могла бы бесплатно обеспечивать содействие в защите прав гражданам, получающим социальные услуги в стационарных организациях, нуждающимся в нем в силу влияния психического расстройства и факта нахождения в стационарной организации на их способности и возможности защищать свои права.

Органам государственной власти субъектов Российской Федерации в сфере социального обслуживания предлагается формировать постоянно действующие комиссии по организации деятельности службы, утверждать регламент ее деятельности. В состав комиссий целесообразно включать представителей органов государственной власти субъекта Российской Федерации в сфере социального обслуживания, общественных и других некоммерческих организаций, осуществляющих деятельность в сфере социальной поддержки инвалидов и оказания юридической помощи, медицинских организаций, средств массовой информации, адвокатов и других лиц.

Разработку регламента деятельности службы в субъекте Российской Федерации целесообразно производить на основании положений вышеупомянутого проекта Федерального Закона. В регламенте деятельности службы необходимо определить полномочия комиссии по организации деятельности службы, требования к ее представителям, порядок их назначения и осуществления ими полномочий.

Среди полномочий представителей службы целесообразно указать следующие:

- проведение в стационарных организациях регулярных консультаций получателей социальных услуг по вопросам реализации и защиты их прав;

- осуществление постоянного приема обращений от получателей социальных услуг по вопросам реализации и защиты их прав;

- помощь во взаимодействии с администрацией стационарной организации в разрешении проблем, возникающих при реализации и защите прав получателей социальных услуг;

- содействие получателям социальных услуг в составлении и подаче обращений в уполномоченные органы и организации, к должностным лицам для защиты их прав, включая содействие в обращении за юридической помощью;

- передача на рассмотрение Комиссии обращений получателей социальных услуг, решение которых находится в компетенции органов государственной власти субъекта Российской Федерации в сфере социального обслуживания, а также вопросы, находящиеся в компетенции стационарной организации, если их не удалось решить в рамках взаимодействия с ее администрацией и пр. 


\section{Заключение}

Адвокация прав граждан при оказании психиатрической помощи в стационарных организациях социального обслуживания - это многомерное явление, включающее в себя не только деятельность по защите прав, свобод и законных интересов определенной категории лиц, но и влияние на общественное мнение, политику в социальной сфере, требующее координации усилий, стратегического мышления, информированности, коммуникации, наличия разъяснительных кампаний, мобилизации государственных и общественных структур.

Развитие деятельности службы по защите прав пациентов, находящихся в медицинских организациях, оказывающих психиатрическую помощь в стационарных условиях, и граждан, проживающих в стационарных организациях социального обслуживания для лиц, страдающих психическими расстройствами, могло бы стать основой, на которой строились бы элементы адвокации, постепенно разрушающие предубеждения и стигмы, которыми овеяна система психиатрической помощи гражданам в России.

Основные законодательные предпосылки для формирования службы в России созданы, необходимы только выражение политической воли на ее создание и мобилизация организационных и финансовых ресурсов в этом направлении.

\section{Список литературы}

1. Аргунова Ю.Н. 2007. Права граждан при оказании психиатрической помощи (вопросы и ответы). М., ФОЛИУМ, 147 с.

2. Аргунова Ю.Н. 2009. Соответствие законодательства Российской Федерации, регулирующего права граждан с психическими расстройствами, Конвенции о защите прав человека и основных свобод, а также рекомендациям Комитета Министров Совета Европы. Независимый психиатрический журнал, 1: 48-60.

3. Абрамян С.К. 2009. Обеспечение и защита прав граждан, страдающих психическими расстройствами. Общество и право, 5 (27): 104-106.

4. Тарасова Е.Н. 2017. Международно-правовое регулирование защиты прав лиц с психическими расстройствами. Вестник Санкт-Петербургской юридической академии, 4 (37): 77-80.

5. Котарев С.Н. 2008. Специальные способы защиты прав недееспособных и ограниченно дееспособных граждан. Научные ведомости Белгородского государственного университета. Серия: Философия. Социология. Право, 14 (54): 160-166.

6. Ларина А.Н., Верещагина О.Н., Анисимова А.А. 2016. Правовые тенденции в развитии психиатрической помощи в России. Международный студенческий научный вестник, 6: 50.

7. Козлова Н.В. 2018. Правовые последствия ограничения дееспособности гражданина, страдающего психическим расстройством. Вестник Московского университета. Серия 11: Право, 3: $26-40$.

8. Семерикова П.В. 2018. Правовое положение лиц с психическими расстройствами в США. Аллея науки, том 4, № 10 (26): 784-786.

9. Sales B.D., Shuman D.W. 1994. Mental health law and mental health care: introduction. American Journal of Orthopsychiatry, 64: 172-179,

10.Perlin M.L. 1994. Law and the delivery of mental health services in the community American Journal of Orthopsychiatry, 64: 194-208,

11.Barker A. 1997. Mental health and the law. BMJ: British medical journal: international edition, 315 (7108): 590-592.

\section{References}

1. Argunova YU.N. 2007. Prava grazhdan pri okazanii psihiatricheksoj pomoshchi (voprosy i otvety). [The rights of citizens in the provision of psychiatric care (questions and answers)]. M., FOLIUM, $147 \mathrm{p}$.

2. Argunova Yu.N. 2009. Sootvetstvie zakonodatel'stva Rossijskoj Federacii, reguliruyushhego prava grazhdan s psixicheskimi rasstrojstvami, Konvencii o zashhite prav cheloveka i osnovny`x svobod, a takzhe rekomendaciyam Komiteta Ministrov Soveta Evropy. [Compliance of the legislation of the 
Russian Federation regulating the rights of citizens with mental disorders, the Convention for the Protection of Human Rights and Fundamental Freedoms, as well as the recommendations of the Committee of Ministers of the Council of Europe]. Nezavisimy`j psixiatricheskij zhurnal, 1: 48-60.

3. Abramyan S.K. 2009. Obespechenie i zashhita prav grazhdan, stradayushhix psixicheskimi rasstrojstvami. [Ensuring and protecting the rights of citizens suffering from mental disorders]. Obshhestvo i pravo, 5 (27): 104-106.

4. Tarasova E.N. 2017. Mezhdunarodno-pravovoe regulirovanie zashhity prav licz s psixicheskimi rasstrojstvami. [International legal regulation of the protection of the rights of persons with mental disorders]. Vestnik Sankt-Peterburgskoj yuridicheskoj akademii, 4 (37): 77-80.

5. Kotarev S.N. 2008. Special'ny`e sposoby`zashhity` prav nedeesposobny`x i ogranichenno deesposobny`x grazhdan. [Special Ways to Protect the Rights of Disabled and Limited Disabled Citizens]. Nauchny`e vedomosti Belgorodskogo gosudarstvennogo universiteta. Seriya: Filosofiya. Sociologiya. Pravo, 14 (54): 160-166.

6. Larina A.N., Vereshhagina O.N., Anisimova A.A. 2016. Pravovy`e tendencii v razvitii psixiatricheskoj pomoshhi v Rossii. [Legal trends in the development of psychiatric care in Russia]. Mezhdunarodny’j studencheskij nauchny`j vestnik, 6: 50.

7. Kozlova N.V. 2018. Pravovy`e posledstviya ogranicheniya deesposobnosti grazhdanina, stradayushhego psixicheskim rasstrojstvom. [Legal consequences of limiting legal capacity of a citizen suffering from a mental disorder]. Vestnik Moskovskogo universiteta. Seriya 11: Pravo, 3: 26-40.

8. Semerikova P.V. 2018. Pravovoe polozhenie licz s psixicheskimi rasstrojstvami v SShA. [The Legal Status of Persons with Mental Disorders in the United States]. Alleya nauki, V. 4, 10 (26): 784786.

9. Sales B.D., Shuman D.W. 1994. Mental health law and mental health care: introduction. American Journal of Orthopsychiatry, 64: 172-179.

10. Perlin M.L. 1994. Law and the delivery of mental health services in the community American Journal of Orthopsychiatry, 64: 194-208,

11. Barker A. 1997. Mental health and the law. BMJ: British medical journal: international edition. V. 315. № 7108. Pp. 590-592.

\section{ИНФОРМАЦИЯ ОБ АВТОРЕ}

Лебедь Анна Викторовна, кандидат юридических наук, юрист региональной благотворительной общественной организации «Центр лечебной педагогики», г. Москва, Россия

\section{INFORMATION ABOUT THE AUTHOR}

Anna V. Lebed, Candidate of Law, Lawyer of the Regional nonprofit social organization "Center for Curative Pedagogics”, Moscow, Russia 